\title{
Research on the Construction of Legal System of Network Security Management under the Background of Information Age
}

\author{
Yu Yueyang \\ East China University of Political Science and Law, Shanghai, 201620
}

Keywords: information age; network security; legal system

\begin{abstract}
As the arrival of the information age, the network has become an indispensable medium in social production and life. The network technology under the background of information age has many advantages, but it is precisely these convenient and rapid characteristics on information exchange that has led to many network security problems. Under the background of information age, the network technology has developed rapidly. Therefore, it is urgent to ensure the network security from the perspective of legislation. On this basis, this paper analyzes the construction of legal system of network security management under the background of information age.
\end{abstract}

\section{Introduction}

Network information is the product of the development of network. Under the background of network age, network information security is very important. It not only involves personal information security, but also national security and social security. Therefore, how to ensure the security of network information has become an important problem under the background of information age. From the state's point of view, the hacker can steal state secrets and scientific research achievements via internet; from the individuals' point of view, their personal privacy or property also can be stolen by the hacker, so, the problem of network security is related to the development of national society and the safety of people's life and property. In general, network security has the characteristics of purpose and diversity. Therefore, a single preventive measure is difficult to work, it is necessary to ensure network security to the greatest extent in the form of legislation from a macro perspective. However, because the legislation in this area is late in our country, and there is no a systematic legal system of network security management at present, so there are many drawbacks in the management of network security. On this basis, this paper analyzes the legal system of network security management under the background of the information age and ponders over the construction of the legal system of network security management.

\section{The Necessity of Constructing the Legal System of Network Security Management under the Background of Information Age.}

In the process of the constant evolution of the information age, the ideology of the public has changed from "legislation is unnecessary" to "legislation is necessary", this is the rule of the development of the information age. In the early days of the information age, people generally thought that there was no need to legislate; however, as the constant development of the application of the network, the network becomes harmful sometimes because of its inherent characteristics as a kind of media under the condition of lack of management. Therefore, people realize that the fundamental regulation must be carried out in accord with the law so as to effectively guarantee the security of network and information. Under the background of the information age, the necessity of constructing the legal system of network security management mainly contains the three points as below:

First, Law is a kind of superstructure that develops with the development of politics, society and economy. At present, it has entered the information age, and the social background of the information age has changed the way of people's work and life. It has changed the methods and perspectives of achieving economic prosperity, changed the overall developmental thinking of the 
society, and related to the further development of the country, the society, and all the people. Therefore, in the information age, there is an urgent need to improve the awareness of network security by means of legislation, at the some time, to strengthen the preventive measures and management methods of network security so as to ensure national security, social security and personal security. Only in this way can we guarantee the social stability and the healthy and systematic development of the social economic.

Second, the construction of the legal system of network security management is also the fundamental method to do well in network security. In the background of the network age, network can be used in all the aspects of people's work and life, and network has changed the social industry development and people's life style and thinking model. At the same time, the spatial, temporal, real-time and interactive characteristics of the network often lead to security problems in the process of using the network, it is urgently need to solve the network security issue by means of legislation so as to prevent the problems such as leakage of the state secret information and scientific research results, leakage of the financial affairs and decision making of the enterprise, the loss of personal information, privacy, and property and so on. By means of legislation, we can control the network security macroscopically, and there are laws to deal with the network security problems, so as to ensure the security of the network to the greatest extent.

Third, Due to the late development of information technology in China, many people have weak security awareness of the network, such as weak security awareness, backward security technology, etc, and these lead to the constant development of the hidden dangers of network security. Some enterprises use the network even without preventive measures of network security, and some other enterprises leak users' information and privacy. The legal system of network security management is to comprehensively manage network security; it is to improve people's security awareness; and it plays an important and positive role in the development of network.

\section{Problems Existing in the Construction of Legal System of Network Security Management under the Background of Information Age}

As the development of the network age, the legal system of network security management in our country has been basically formed, but there are still a lot of immature situations, the biggest problem is the lack of fundamental law. By the investigation, we can find that in the current legal system of network security management, local regulations occupy the vast majority, but the proportion of laws is relatively small. In terms of the effect of the laws, the level of effectiveness of local regulations is relatively low, the scope of its application is limited, and due to the weak design ideas, limited emphasis of application and other weaknesses, the regulations may lead to conflict between each other, it also can not be used as the basis of the court decision sometimes, so that the regulations can not solve the relevant problems about network security. What's more, the most important thing is that at present our country does not have any fundamental law on network information security, which leads to the lack of basic principles and systems in the process of making laws and regulations.

The current laws on network security in China include: 7 clauses in the Decisions of the NPC Standing Committee on maintaining Internet Security; 31 clauses in Regulations of the People's Republic of China on the Security Protection of Computer Information Systems; 27 clauses in Management Method of Internet Information Service, etc. From the perspective of contents of these clauses, the contents are limited, the contents are also not detailed, so to speak, there are very imperfect problems, and these all restrict the construction of the legal system of network security management.

In the construction of network security management laws, other laws related to network security should also be improved, only the systematic combination of the laws is the complete legal system of network security management, such as Personal Data Protection Law, Telecommunication Law and so on. However, from the current situation, there are still some serious problems in the laws related to network security management in our country.

From the perspective of the rights, the rights involved in the security of network information 
include the right of privacy, the secret of communication, the intellectual property, the freedom of speech and so on. These rights are mainly come from the General Rules of the Civil Law, the Contract Law, the Copyright Law, the Administrative license Law, the Anti-Unfair Competition Law, the Technical Contract Law, the National Safety Law, the Bank Law, and so on. Although there are laws in some cases of problems, but under the background of the information age, when there will be some problems, a variety of different legal definitions are clearly difficult to solve the problems of network security in the information age. At the same time, the network security includes telecommunication, computer, information service, e-government affairs, information disclosure and utilization, electronic commerce, electronic finance, modern logistics and so on, although every field has the relevant law, but there is no one is specifically about the security of the network and that can coordinate all the aspects, so the relevant legal construction is not complete.

\section{The Optimizing Strategies for the Construction of Legal System of Network Security Management under the Background of Information Age}

At present, many developed countries have built the fundamental law about network information security, such as the Federal Information Security Management Act and the Computer Security Act in the United States. Therefore, our country must also update the concept of the legislation on the network security and speed up the construction of the fundamental law of the network information. At present, the theoretical research on the network information law provides a certain practical basis for the legislative work of the network information. However, in essence, there are certain deficiencies in both depth and strength, and the draw up law is not formed to meet the needs of the legislation. Therefore, it is necessary to strengthen the research and draft the fundamental about network security of our country as soon as possible. We can learn from the experiences of foreign countries, have a good understanding about the development trend of foreign network information legislation, and combine the actual situation of our country, start from the national conditions of us, absorb and learn from foreign legislative achievements boldly, so as to draw up the fundamental law of network security in accordance with the socialism with Chinese characteristics and the actual background of the network age.

On this basis, we also need to establish the necessary feedback mechanism to ensure the effectiveness of the enforcement of the fundamental law on network security, so as to ensure the actual effect of the enforcement of laws and regulations, to find out problems timely and take effective countermeasures, and to ensure the smooth implementation of the laws and regulations that are related to network information. we should not only consider how to determine the negative legal consequences of the law, but also consider the positive legal consequences that are definitely positive, and improve the comprehensiveness of the fundamental law on network information, so that we can ensure the effective construction of the fundamental law of network information.

Network security under the background of information age is a kind of systematic management work, which involves many fields and aspects, such as basic information network, internal office of the party and government, national defense information, taxation, etc; these contents also need to be brought into the legal system of network security management. As mentioned in the above analysis, although there are supporting laws in various fields of network security, however, there is still no a set of laws that is applicable to network security under the background of the information age. Therefore, it is necessary to improve the supporting legal content. The emphasis of the supporting legal content should be placed on ranked protection, monitoring system, network trust, and information protection and so on, so as to strengthen legal efficiency, to avoid the hysteretic nature that is caused by the rapid development of the network, and to enhance the foresight of supporting laws. The law should meet the special requirements of network technology, eliminate the possibility of blocking the development of technology, and improve the applicability of the laws to the information age.

In the supporting process, it is necessary to take the actual development of our country into account, to avoid the void the empty clauses in the laws, to allow the law to show practical judicial significance, and to comply with the existing legal system if the contents belong to the existing 
legal system; if it is not part of the current legal system, it is necessary to make bold breakthroughs. We oppose legislation at every turn, in the process of legislation, it is necessary to stipulate some clauses for management, and also to stipulate some clauses that can promote the healthy development of the network information technology and the network information industry. More importantly, it is necessary to have the clauses on self-discipline for the practitioners of the network information industry; in the implementation of the laws, We should try our best to perfect the administrative enforcement system of network information security, to train a group of professional teams with professional knowledge on network information for the enforcement of the laws, so as to ensure the perfection of the legal system of network security management to the greatest extent, and ensure the security of network.

\section{Conclusion}

The construction of legal system of network security management is a huge project, it not only involves many aspects but also and a lot of contents about management, under the background of the information age, it is of great practical significance to construct a legal system of network security management according to the actual situation of China. Therefore, we need to study and deliberate constantly and aim at the characteristics of information age and network security. Relying on the basic legislation and the improvement of the supporting laws, we should consider the construction strategy of the legal system of network security management, ensure the network security to the greatest extent, and promote the steady development of our country in network age.

\section{References}

[1] Tian Wenying, Zhao Gang. Analysis on Adjustment of Laws on Network Information Security [J]. Journal of Intelligence, 2015(03).

[2] Meng Fanming. On China's Network legislation [J]. Journal of Environmental Management College of China, 2014(04).

[3] Ma Haiqun. Problems and the Developmental Countermeasures of China's Network Legislation [J]. Network Security Technology \& Application, 2011(04).

[4] Yang Dan. Research on the Network Information Security of Transportation Logistics Platform [D]. Wuhan University of Technology, 2005.

[5] Leng Jian. Research and Design on Certificate Management System in Network Information Security [D]. Hunan University, 2011.

[6] Wang Chao. Research and Design on Intrusion Detection System of Computer Network Security [D]. University of Electronic Science and Technology of China, 2017. 